\title{
Pulmonary metastasectomy: an overview
}

\author{
Francesco Petrella ${ }^{1,2}$, Cristina Diotti ${ }^{1}$, Arianna Rimessi ${ }^{1}$, Lorenzo Spaggiari ${ }^{1,2}$ \\ ${ }^{1}$ Department of Thoracic Surgery, European Institute of Oncology, Milan, Italy; ${ }^{2}$ Department of Oncology and Hemato-oncology, University of \\ Milan, Milan, Italy \\ Contributions: (I) Conception and design: F Petrella, L Spaggiari; (II) Administrative support: C Diotti, A Rimessi; (III) Provision of study materials or \\ patients: C Diotti, A Rimessi; (IV) Collection and assembly of data: F Petrella C Diotti, A Rimessi; (V) Data analysis and interpretation: All authors; \\ (VI) Manuscript writing: All authors; (VII) Final approval of manuscript: All authors. \\ Correspondence to: Francesco Petrella, MD. Department of Thoracic Surgery, European Institute of Oncology, Via Ripamonti, 435, 20141 Milan, \\ Italy. Email: francesco.petrella@ieo.it; francesco.petrella@unimi.it.
}

\begin{abstract}
Metastasectomy is the most frequent surgical resection undertaken by thoracic surgeons, being the lung the second common site of metastases. The present oncological criteria for pulmonary metastasectomy are: (I) the primary cancer need to be controlled or controllable; (II) no extrathoracic metastasis - that is not controlled or controllable-exists; (III) all of the tumor must be resectable, with adequate pulmonary reserve; (IV) there are no alternative medical treatment options with lower morbidity. General favourable prognostic features in patients with pulmonary metastases are: (I) one or few metastases; (II) long disease free interval; (III) normal CEA levels in colorectal cancers. Negative predictive features in patients candidate to pulmonary metastasectomies are: (I) active primary cancer; (II) extrathoracic metastases; (III) inability to obtain surgical radicality; (IV) mediastinal lymphatic spread. The lack of controlled trials and studies limited by short follow-up and small cohorts did not allow to overcome some skepticism; moreover, the heterogeneity of these patients in terms of demographic, biologic and histologic characteristics represents a clear limit even in the largest series. On the basis of present knowledge, without results coming from on-going randomized trials, radical resection, histology, and disease free interval seem to be independent prognostic factors identifying a cohort of patients maximally benefitting from lung metastasectomy.
\end{abstract}

Keywords: Lung metastases; metastasectomy; pulmonary function

Submitted Jan 11, 2017. Accepted for publication Mar 22, 2017.

doi: $10.21037 /$ jtd.2017.03.175

View this article at: http://dx.doi.org/10.21037/jtd.2017.03.175

\section{Introduction}

Metastasectomy is the most frequent surgical resection undertaken by thoracic surgeons (1). Lung is the second common site of metastases (1) and the role of pulmonary metastasectomy has been widely investigated by the 1970s (2) culminating in an important landmark publication in 1997 reporting the results from the International Registry of Lung Metastasectomy $(3,4)$.

From 2000 through 2011 the performance of all types of metastasectomy-irrespective of the anatomic target site (liver, lung, brain and adrenal glands)—increased substantially across common cancer types, notwithstanding various advances in systemic therapies; metastasectomy was performed more safely, despite increasing patient comorbidities and lung metastasectomies increased significantly, following liver metastasectomies that demonstrated the highest rate of increase of any metastatic site (5).

Colorectal neoplasms are the commonest epithelial lesions for which pulmonary metastasectomy is indicated (1) and they are the only type of primary cancer metastatic to the lungs for which a randomized trial is ongoing, comparing active monitoring versus active monitoring with pulmonary metastasectomy (6).

All the other types of primary cancers metastatic to the lungs (germ cell tumors, melanoma, sarcoma, gyneacological, urological, upper gastrointestinal as well as thyroid and kidney cancers) have been studied only by 
non-randomized studies and the evidence for pulmonary metastasectomy still remains unproven (1).

\section{Oncologic principles and surgical aspects}

The present oncological criteria for pulmonary metastasectomy are: (I) the primary cancer need to be controlled or controllable (II) no extrathoracic metastasisthat is not controlled or controllable-exists (III) all of the tumor must be resectable, with adequate pulmonary reserve (IV) there are no alternative medical treatment options with lower morbidity (7).

Patients with favourable prognostic factors can survive longer irrespective of treatments while favorable predictive factors are those allowing to discriminate patients benefitting from particular treatments (8); general favourable prognostic features in patients with pulmonary metastases are: (I) one or few metastases; (II) long disease free interval; (III) normal CEA levels in colorectal cancers. Negative predictive features in patients candidate to pulmonary metastasectomies are: (I) active primary cancer; (II) extrathoracic metastases; (III) inability to obtain surgical radicality; (IV) mediastinal lymphatic spread (1).

It is estimated that $75 \%$ or more of patients with pulmonary nodules will also have metastases to extrathoracic sites; only $15 \%$ to $25 \%$ of patients have lesions confined to the lung and are appropriate candidates for curative resection (7). For this reason, staging for metastatic disease outside of the lung is performed prior to pulmonary resection, by CT of the chest and abdomen and, in selected cases, by PET scan and brain imaging with either MRI or CT scan (9).

Intrathoracic lymph node involvement is associated with decreased survival after pulmonary metastasectomy; the data are most convincing for colorectal and renal cell cancers and there is limited evidence as to whether mediastinal lymphadenectomy leads to improved survival in patients receiving lung metastasectomy (10-12).

Lung function testing is an important component to the preoperative evaluation of patients undergoing metastasectomy: although sublobar resections are most often used, cumulative parenchymal loss must be considered in the setting of multiple lesions $(7,13)$; moreover, although "parenchyma-sparing" procedures still remain the gold standard, major pulmonary resections for treating lung metastases-including pneumonectomy or pulmonary resection with en bloc resection of the chest wall or other major structures (diaphragm, pericardium, superior vena cava) - have been reported with low mortality and morbidity rates and an acceptable long-term survival, when performed in selected patients susceptible to complete resection (14).

Patients with a predicted postoperative FEV 1 or DLCO between $30 \%$ and $60 \%$ predicted should have additional risk stratification with an exercise test, such as shuttle walk test or stair climb, prior to proceeding with surgery; patients with postoperative predicted FEV 1 or DLCO less than $30 \%$ should undergo formal cardiopulmonary exercise testing with measurement of maximal oxygen consumption (15).

Both video-assisted thoracic surgical (VATS) techniques and open thoracotomy are accepted as appropriate incisions for performing pulmonary metastasectomy (16); on one side, open techniques have been shown to lead to the detection and hence, resection of more metastases than VATS techniques, in particular in case of nodule deeply embedded within the parenchyma (16-18). On the contrary VATS has been considered a preferable approach due to superior functional outcome, offering a shorter hospital stay, a shorter duration of chest tube drainage and epidural analgesia (19) (Figures 1,2).

\section{Colorectal cancers}

A quarter of patients with colorectal cancer have metastatic lesions at diagnosis and in nearly half of them, metastases will develop, often in liver or lung or both (20). Surgery has been consistently reported as a potentially curative option for liver-limited disease, with 5 -year survival of $30-40 \%$ (21); in $10-15 \%$ of cases lung metastases are documented at advanced disease and are diagnosed mostly as multiple or bilateral metastases, with only $2 \%$ to $7 \%$ a single lesion (22).

The practice of pulmonary metastasectomy is widespread, having a consensus regarding the effectiveness of the procedure with 5 -year survival rates approximately $30-50 \%$ (23); however, despite its widespread use, no results from prospective controlled or randomized trials are now available to confirm the evidence-based benefit of lung surgery (20).

Recently the GLIDA trial disclosed that early diagnosis of neoplasm recurrence is not related to overall survival implementation (24).

As reported before, the PulMiCC trial-comparing active monitoring versus active monitoring with pulmonary metastasectomy in patients suffering from pulmonary metastases from colorectal neoplasms-is ongoing and it will be probable able to provide evidence with respect to pulmonary metastasectomy in colorectal cancer $(6,25)$. 


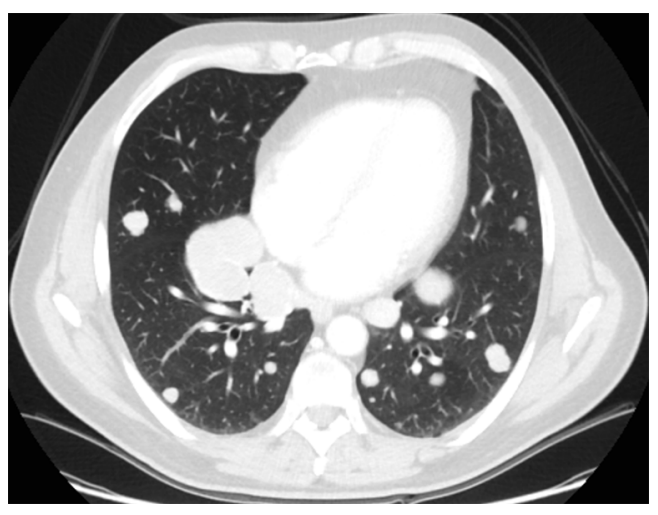

Figure 1 Multiple, bilateral lung metastases not amenable of radical resection because of number, location and dimensions of the lesions.

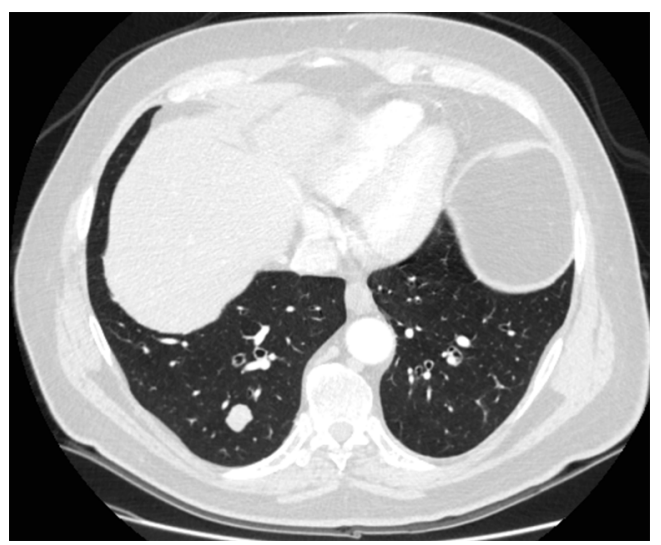

Figure 2 Single metastasis of the right lower lobe amenable of radical resection.

A recent study disclosed that major anatomic resection with lymphadenectomy for pulmonary metastasectomy can be considered in selected patient with sufficient functional reserve to improve the disease specific survival and disease free survival (26); nowadays is commonly stated that radicality of surgery is the major prognostic indicator of long-term survival, whereas number and distribution of lung metastases, primary stage at diagnosis, elevated prethoracotomy carcinoembryonic antigen levels, disease-free interval, mediastinal or hilar lymphnode involvement, presence of solitary liver localization and systemic therapy are otherwise considered in retrospective studies (20).

\section{Urinary tract cancers}

After the initial report, there have been anecdotal reports that suggested the potential benefit of metastasectomy on survival of patients with urinary tract cancer $(26,27)$. However, due to the rarity of oligometastases associated with advanced urinary tract carcinoma, little is known about the efficacy of metastasectomy and prognostic factors (27).

Despite a favorable initial response rate to chemotherapy (44-64\%), long-term overall survival is achieved by only a minority of patients with metastatic urinary tract cancer and the median overall survival for this disease typically plateaus at approximately 14 to 15 months (28). In studies investigating the contribution of lung metastasectomy in patients with metastatic urinary tract cancer, overall survival was 30 months, longer when compared with that of patients who received mainly systemic chemotherapy (27).

For patients with isolated pulmonary metastases, metastasectomy for single lung metastasis is statistically related to longer time to progression than for patients receiving multiple lung metastasectomies but a longer time to progression does not translate into a longer overall survival (27).

The present recommended strategy for consolidative surgery for metastatic tract cancer suggests to offer this treatment to patients who: (I) have responded to previous chemotherapy; (II) have disease recurrence at the initial or sole metastatic site; (III) have a tumor that is surgically resectable with clear margins; (IV) have a documented period of disease stability without evidence of rapid disease progression (29).

In case of renal cell carcinoma, patients receiving lung metastasectomy disclosed a significant survival advantage, mainly in case of isolated pulmonary metastases, although a survival advantage was observed even in patients with extrathoracic synchronous metastases receiving pulmonary resection (30); it is not clear if patients should receive lung metastasectomy when radical macroscopic radicality could not be achieved (30).

\section{Osteosarcoma and soft tissue sarcomas}

Sarcoma comprises a heterogeneous group of histologic subtypes with a propensity to metastasize to the lungs. Isolated pulmonary metastases occur in as many as $20 \%$ of patients diagnosed with soft tissue sarcoma and as many as 
$40 \%$ in those with a primary bone sarcoma (31).

Osteosarcoma is the most common primary cancer in young patients (32); three-fourths of patients metastases at diagnosis and about $30-40 \%$ of patients-without metastatic disease at diagnosis-develop subsequently lung metastases (33).

Lung metastasectomy provides prolonged survival and should always be considered when safely feasible (34); better outcomes are reported in patients with single-side metastatic disease and longer disease free interval (33); although the volume of lung lesion was not statistically related to postoperative prognosis, patients requiring a major resection-because of centrally located lesionspresented a poorer prognosis (35); post-chemotherapy necrosis $<90 \%$ in the primary tumor, developing metastases during chemotherapy and chondroblastic subtype are predictors of poor prognosis (36).

Soft tissue sarcomas are an eterogeneous group of mesenchymal cancers (37); they frequently metastasize to the lung, despite primary tumor radical resection (38).

Pulmonary metastasectomy is considered the gold standard treatment in case of isolated lung metastases, as several studies have shown a better survival in patients who received metastasectomy $(39,40)$.

According to Giuliano et al., younger age at diagnosis and low-grade tumors with longer disease free interval offer the greatest survival advantage to radically resected patients (37).

\section{Pediatric cancers}

Primary solid cancers of children, such as Ewing's sarcoma, hepatoblastoma, Wilms' tumor and osteosarcomas, commonly metastasize to the lung, having a negative prognostic impact (41).

Several reports have shown prolonged survival after pulmonary metastasectomy in selected patients presenting with isolated lung metastases, mainly in case of osteosarcoma; however prognostic factors are still unclear $(42,43)$. The 5 -year survival rates-reported by studies on the role of surgery for pulmonary metastases in pediatric patientsranged from $20 \%$ to $40 \%(44,45)$.

Tronc et al. reported that pulmonary metastasectomy is a safe and potentially curative treatment in pediatric patients presenting secondary lung lesions form solid tumors of different histologies.

The low morbidity rate-as well as the absence of mortality-justify an aggressive surgical approach combined with chemotherapy; ideal indications for lung metastasectomy are a small number of pulmonary metastases and a long disease free interval (41).

In a recent report from Stanelle et al., the influence of pulmonary metastasectomy for metastatic synovial sarcoma in pediatric/adolescent patients has been investigated, disclosing that pulmonary metastasectomy may be associated with improved survival if complete resection is achieved (46).

\section{Head and neck cancers}

The lungs are the most common target of distant metastases form head and neck cancers, including squamous cell carcinoma, adenoid-cystic carcinoma and other histologies $(47,48)$. These metastatic cancers scarcely respond to chemotherapy, and thus surgery has become a valid curative alternative if all the general principles of lung metastasectomy are respected.

Five-year survival after lung metastasectomy of head and neck cancers is reported to range between 50-60\% (49); older age ( $\geq 60$ years), short disease free interval ( $<26$ months) and histology of squamous cell carcinoma have been reported to have an adverse impact on clinical outcome $(47,50)$; similarly oral cancers, mediastinal lymph nodes spreading and pleural infiltration conditionate a worse prognosis (51).

Patients receiving pulmonary metastasectomy of adenoid cystic carcinoma-a slow growing tumor-present an estimated 5 -year survival rate of $84 \%$ (52); on the other hand, 5-year survival rate of patients undergoing lung resection for squamous cell carcinoma ranges between $26.5 \%$ and $43.0 \%(53,54)$.

Lung metastases and primary squamous cell lung cancer are difficult to be histopathologically distinguished; differential diagnosis is mainly based on clinical aspects (site of lung lesion, tumor stage, disease free interval) while, so far, genetic analysis does not allow to discriminate between metastases of SCC of the head and neck and primary SCC lung cancer (51).

\section{Gynecologic cancers}

The incidence of pulmonary metastasis of gynecologic cancers ranges between $2.3-4.6 \%$ (55) being higher in patients suffering from sarcoma or choriocarcinoma than in patients affected by epithelial gynecologic cancers like cervical, endometrial or ovarian carcinomas (56).

At the moment, The Clinical Practice Guidelines in Oncology developed by the National Comprehensive Cancer Network (NCCN) suggest surgical resection for 
removable regional uterine cancer metastasis (55). Several studies have shown a 5 -year survival rate from $32.9 \%$ to $46.8 \%(57,58)$.

Lung metastasectomy-when is a low risk-procedurehas been shown to ameliorate the long term survival; moreover, pulmonary resection, for single lung metastasis might offer a better prognosis not only for patients with a long relapse free interval but also for patients with tumors resistant to chemotherapy or re-recurrent ones (56). Patients presenting more than three pulmonary lesions and with respiratory symptoms, related to lung metastases, could expect to have worse prognosis after lung metastases resection (55).

\section{Other malignancies}

\section{Melanoma}

The lungs are the most frequent site of visceral metastases from melanoma, comprising $15 \%$ to $35 \%$ of patients with metastatic melanoma (59). Several studies have shown improved survival after pulmonary metastasectomy, with median survival from 10 to 28 months and 5 -year survival rates from $4 \%$ up to $14-35 \%(60,61)$. Positive prognostic factors include complete resection, disease-free interval greater than 1 year, fewer than three pulmonary nodules, absence of extrathoracic and lymph node metastasis, and response to chemotherapy/immunotherapy $(62,63)$.

\section{Gastric cancers}

The role of lung metastasectomy in gastric cancer patients is still unclear (64). As many patients suffering from lung metastases form gastric cancers present synchronous carcinomatous lymphangitis or pleuritis, pulmonary metastasectomy has been rarely reported in this setting, thus only few data being available on short and long term outcomes $(65,66)$.

Lung metastasectomy for gastric cancer pulmonary metastases has been only rarely reported, therefore we conclude that pulmonary resection of gastric metastases has no evident role in the routinely clinical management of metastatic gastric patients and it could be occasionally proposed only for highly selected patients (64).

\section{Nonseminomatous germ cell tumors}

Nonseminomatous germ cell tumors of testicular origin are the most frequent cancers among male patients younger than 30 (67); but lungs and the retroperitoneal space are commonly the starting site of metastatic spread (68).

Indications for lung metastasectomy in this cohort of patients are: (I) lack of response to chemotherapy; (II) only partial response and then recurrence while on chemotherapy; (III) recurrence after standard and second line treatments; (IV) to check if residual tumor is still present; and (V) to resect expanding benign teratomatous aspects of the tumor (69). Postoperative 30-day mortality rate is reported to range between 0.0 and 0.036 while 5 -year survival rates range between $73 \%$ and $94 \%$ (68).

\section{Breast cancers}

The lung is a frequent metastatic site for recurrent breast cancer but the role of pulmonary resection is still under debate, in particular in the light of excellent results of nonsurgical treatments, like hormono or chemotherapy.

Yhim et al. analyzed clinical outcomes of patients suffering from recurrent breast-cancer with less than four pulmonary metastases, treated with systemic treatment alone or lung resection and then systemic treatment, disclosing that pulmonary metastasectomy can be an effective therapeutic option for patients with few and small metastases, irrespective of poor-prognosis aspects (70). Similarly Planchard et al. demonstrated that pulmonary metastasectomy from breast carcinoma was associated with a significant 5 -year survival rate of $45 \%$, but were not able to discriminate whether this result was due to the surgical procedure itself or to the selection of patients (71); the authors emphasized that when resection is evaluated this cohort of patients, both the size of the largest metastasis and the disease free interval should be carefully considered (71).

\section{Conclusions}

Since the establishment of the International Registry of Lung Metastases in the 1990s (3), pulmonary metastasectomy has been an area of debate between surgeons and oncologists (72). However, the lack of controlled trials and studies limited by short follow-up and small cohorts did not allow to overcame some skepticism; moreover, the heterogeneity of these patients in terms of demographic, biologic and histologic characteristics represents a clear limit even in the largest series $(73,74)$.

On the basis of present knowledge, without results coming from on-going randomized trials, radical resection, 
histology, and disease free interval seem to be independent prognostic factors identifying a cohort of patients maximally benefitting from lung metastasectomy.

\section{Acknowledgements}

None.

\section{Footnote}

Conflicts of Interest: The authors have no conflicts of interest to declare.

\section{References}

1. Treasure T, Milošević M, Fiorentino F, et al. Pulmonary metastasectomy: what is the practice and where is the evidence for effectiveness? Thorax 2014;69:946-9.

2. McCormack PM, Martini N. The changing role of surgery for pulmonary metastases. Ann Thorac Surg 1979;28:139-45.

3. Pastorino U, Buyse M, Friedel G, et al. Long-term results of lung metastasectomy: prognostic analyses based on 5206 cases. J Thorac Cardiovasc Surg 1997;113:37-49.

4. Pastorino $\mathrm{U}$. The development of an international registry. J Thorac Oncol 2010;5:S196-7.

5. Bartlett EK, Simmons KD, Wachtel H, et al. The rise in metastasectomy across cancer types over the past decade. Cancer 2015;121:747-57.

6. Royal Brompton \& Harefield NHS Foundation Trust, University of Cambridge, University of Sussex. A Randomised Trial of Pulmonary Metastasectomy in Colorectal Cancer (PulMiCC). Available online: https:// clinicaltrials.gov/ct2/show/NCT01106261

7. Erhunmwunsee L, Tong BC. Preoperative Evaluation and Indications for Pulmonary Metastasectomy. Thorac Surg Clin 2016;26:7-12.

8. Simms L, Barraclough H, Govindan R. Biostatistics primer: what a clinician ought to know--prognostic and predictive factors. J Thorac Oncol 2013;8:808-13.

9. Kondo H, Okumura T, Ohde Y, et al. Surgical treatment for metastatic malignancies. Pulmonary metastasis: indications and outcomes. Int J Clin Oncol 2005;10:81-5.

10. Veronesi G, Petrella F, Leo F, et al. Prognostic role of lymph node involvement in lung metastasectomy. J Thorac Cardiovasc Surg 2007;133:967-72.

11. Reinersman JM, Wigle DA. Lymphadenectomy During Pulmonary Metastasectomy. Thorac Surg Clin 2016;26:35-40.
12. Sihag S, Muniappan A. Lymph Node Dissection and Pulmonary Metastasectomy. Thorac Surg Clin 2016;26:315-23.

13. Petrella F, Chieco P, Solli P, et al. Which factors affect pulmonary function after lung metastasectomy? Eur J Cardiothorac Surg 2009;35:792-6.

14. Casiraghi M, Maisonneuve P, Brambilla D, et al. The role of extended pulmonary metastasectomy. J Thorac Oncol 2015;10:924-9.

15. Brunelli A, Kim AW, Berger KI, et al. Physiologic evaluation of the patient with lung cancer being considered for resectional surgery: Diagnosis and management of lung cancer, 3rd ed: American College of Chest Physicians evidence-based clinical practice guidelines. Chest 2013;143:e166S-90S.

16. Downey RJ, Bains MS. Open Surgical Approaches for Pulmonary Metastasectomy. Thorac Surg Clin 2016;26:13-8.

17. Petrella F, Leo F, Dos Santos NA, et al. "Circular clamp" excision: a new technique for lung metastasectomy. J Thorac Cardiovasc Surg 2009;138:244-5.

18. Bini A, Grazia M, Petrella F, et al. Multiple chondromatous hamartomas of the lung. Interact Cardiovasc Thorac Surg 2002;1:78-80.

19. Numan RC, Baas P, Klomp HM, et al. Optimal surgical management of pulmonary metastases: VATS versus thoracotomy. Respirology 2016;21:188-90.

20. Zampino MG, Maisonneuve P, Ravenda PS, et al. Lung metastases from colorectal cancer: analysis of prognostic factors in a single institution study. Ann Thorac Surg 2014;98:1238-45.

21. Simmonds PC, Primrose JN, Colquitt JL, et al. Surgical resection of hepatic metastases from colorectal cancer: a systematic review of published studies. Br J Cancer 2006;94:982-99.

22. Limmer S, Unger L. Optimal management of pulmonary metastases from colorectal cancer. Expert Rev Anticancer Ther 2011;11:1567-75.

23. Fiorentino F, Vasilakis C, Treasure T. Clinical reports of pulmonary metastasectomy for colorectal cancer: a citation network analysis. Br J Cancer 2011;104:1085-97.

24. Rosati G, Ambrosini G, Barni S, et al. A randomized trial of intensive versus minimal surveillance of patients with resected Dukes B2-C colorectal carcinoma. Ann Oncol 2016;27:274-80.

25. Treasure T, Macbeth F. The GILDA trial finds no survival benefit from intensified screening after primary resection of colorectal cancer: the PulMiCC trial tests the survival 
benefit of pulmonary metastasectomy for detected asymptomatic lung metastases. Ann Oncol 2016;27:745.

26. Cowles RS, Johnson DE, McMurtrey MJ. Long-term results following thoracotomy for metastatic bladder cancer. Urology 1982;20:390-2.

27. Kim T, Ahn JH, You D, et al. Pulmonary Metastasectomy Could Prolong Overall Survival in Select Cases of Metastatic Urinary Tract Cancer. Clin Genitourin Cancer 2015;13:e297-304.

28. von der Maase H, Sengelov L, Roberts JT, et al. Longterm survival results of a randomized trial comparing gemcitabine plus cisplatin, with methotrexate, vinblastine, doxorubicin, plus cisplatin in patients with bladder cancer. J Clin Oncol 2005;23:4602-8.

29. Siefker-Radtke AO, Walsh GL, Pisters LL, et al. Is there a role for surgery in the management of metastatic urothelial cancer? The M. D. Anderson experience. J Urol 2004;171:145-8.

30. Alt AL, Boorjian SA, Lohse CM, et al. Survival after complete surgical resection of multiple metastases from renal cell carcinoma. Cancer 2011;117:2873-82.

31. Digesu CS, Wiesel O, Vaporciyan AA, et al. Management of Sarcoma Metastases to the Lung. Surg Oncol Clin N Am 2016;25:721-33.

32. Ciccarese F, Bazzocchi A, Ciminari R, et al. The many faces of pulmonary metastases of osteosarcoma: Retrospective study on 283 lesions submitted to surgery. Eur J Radiol 2015;84:2679-85.

33. Briccoli A, Rocca M, Salone M, et al. High grade osteosarcoma of the extremities metastatic to the lung: long-term results in 323 patients treated combining surgery and chemotherapy, 1985-2005. Surg Oncol 2010;19:193-9.

34. Kim S, Ott HC, Wright CD, et al. Pulmonary resection of metastatic sarcoma: prognostic factors associated with improved outcomes. Ann Thorac Surg 2011;92:1780-6; discussion 1786-7.

35. Rasalkar DD, Chu WC, Lee V, et al. Pulmonary metastases in children with osteosarcoma: characteristics and impact on patient survival. Pediatr Radiol 2011;41:227-36.

36. Salah S, Toubasi S. Factors predicting survival following complete surgical remission of pulmonary metastasis in osteosarcoma. Mol Clin Oncol 2015;3:157-62.

37. Giuliano K, Sachs T, Montgomery E, et al. Survival Following Lung Metastasectomy in Soft Tissue Sarcomas. Thorac Cardiovasc Surg 2016;64:150-8.

38. Potter DA, Glenn J, Kinsella T, et al. Patterns of recurrence in patients with high-grade soft-tissue sarcomas. J Clin Oncol 1985;3:353-66.

39. Robinson MH, Sheppard M, Moskovic E, et al. Lung metastasectomy in patients with soft tissue sarcoma. Br J Radiol 1994;67:129-35.

40. Billingsley KG, Burt ME, Jara E, et al. Pulmonary metastases from soft tissue sarcoma: analysis of patterns of diseases and postmetastasis survival. Ann Surg 1999;229:602-10; discussion 610-2.

41. Tronc F, Conter C, Marec-Berard P, et al. Prognostic factors and long-term results of pulmonary metastasectomy for pediatric histologies. Eur J Cardiothorac Surg 2008;34:1240-6.

42. Goorin AM, Delorey MJ, Lack EE, et al. Prognostic significance of complete surgical resection of pulmonary metastases in patients with osteogenic sarcoma: analysis of 32 patients. J Clin Oncol 1984;2:425-31.

43. Kempf-Bielack B, Bielack SS, Jürgens H, et al. Osteosarcoma relapse after combined modality therapy: an analysis of unselected patients in the cooperative osteosarcoma study group (COSS). J Clin Oncol 2005;23:559-68.

44. Pfannschmidt J, Klode J, Muley T, et al. Pulmonary resection for metastatic osteosarcomas: a retrospective analysis of 21 patients. Thorac Cardiovasc Surg 2006;54:120-3.

45. Harting MT, Blakely ML, Jaffe N, et al. Long-term survival after aggressive resection of pulmonary metastases among children and adolescents with osteosarcoma. J Pediatr Surg 2006;41:194-9.

46. Stanelle EJ, Christison-Lagay ER, Wolden SL, et al. Pulmonary metastasectomy in pediatric/adolescent patients with synovial sarcoma: an institutional review. J Pediatr Surg 2013;48:757-63.

47. Yotsukura M, Kinoshita T, Kohno M, et al. Survival predictors after resection of lung metastases of head or neck cancers. Thorac Cancer 2015;6:579-83.

48. Galetta D, Petrella F, Leo F, et al. Treatment of pulmonary metastases from primary intraosseous odontogenic carcinoma. Lancet Oncol 2006;7:272-3.

49. Haro A, Yano T, Yoshida T, et al. Results of a surgical resection of pulmonary metastasis from malignant head and neck tumor. Interact Cardiovasc Thorac Surg 2010;10:700-3.

50. Wedman J, Balm AJ, Hart AA, et al. Value of resection of pulmonary metastases in head and neck cancer patients. Head Neck 1996;18:311-6.

51. Winter H, Meimarakis G, Hoffmann G, et al. Does surgical resection of pulmonary metastases of head 
and neck cancer improve survival? Ann Surg Oncol 2008;15:2915-26.

52. Liu D, Labow DM, Dang N, et al. Pulmonary metastasectomy for head and neck cancers. Ann Surg Oncol 1999;6:572-8.

53. Shiono S, Kawamura M, Sato T, et al. Pulmonary metastasectomy for pulmonary metastases of head and neck squamous cell carcinomas. Ann Thorac Surg 2009;88:856-60.

54. Mazer TM, Robbins KT, McMurtrey MJ, et al. Resection of pulmonary metastases from squamous carcinoma of the head and neck. Am J Surg 1988;156:238-42.

55. Paik ES, Yoon A, Lee YY, et al. Pulmonary metastasectomy in uterine malignancy: outcomes and prognostic factors. J Gynecol Oncol 2015;26:270-6.

56. Adachi M, Mizuno M, Mitsui H, et al. The prognostic impact of pulmonary metastasectomy in recurrent gynecologic cancers: a retrospective single-institution study. Nagoya J Med Sci 2015;77:363-72.

57. Clavero JM, Deschamps C, Cassivi SD, et al. Gynecologic cancers: factors affecting survival after pulmonary metastasectomy. Ann Thorac Surg 2006;81:2004-7.

58. Yamamoto K, Yoshikawa H, Shiromizu K, et al. Pulmonary metastasectomy for uterine cervical cancer: a multivariate analysis. Ann Thorac Surg 2004;77:1179-82.

59. Wei IH, Healy MA, Wong SL. Surgical treatment options for stage IV melanoma. Surg Clin North Am 2014;94:1075-89, ix.

60. Neuman HB, Patel A, Hanlon C, et al. Stage-IV melanoma and pulmonary metastases: factors predictive of survival. Ann Surg Oncol 2007;14:2847-53.

61. Essner R, Lee JH, Wanek LA, et al. Contemporary surgical treatment of advanced-stage melanoma. Arch Surg 2004;139:961-6; discussion 966-7.

62. Harpole DH Jr, Johnson CM, Wolfe WG, et al. Analysis of 945 cases of pulmonary metastatic melanoma. J Thorac Cardiovasc Surg 1992;103:743-8; discussion 748-50.

63. Tafra L, Dale PS, Wanek LA, et al. Resection and adjuvant immunotherapy for melanoma metastatic to the lung and thorax. J Thorac Cardiovasc Surg 1995;110:119-28; discussion 129.

Cite this article as: Petrella F, Diotti C, Rimessi A, Spaggiari L. Pulmonary metastasectomy: an overview. J Thorac Dis 2017;9(Suppl 12):S1291-S1298. doi: 10.21037/jtd.2017.03.175
64. Aurello P, Petrucciani N, Giulitti D, et al. Pulmonary metastases from gastric cancer: Is there any indication for lung metastasectomy? A systematic review. Med Oncol 2016;33:9.

65. Funakoshi T, Yasui H, Boku N, et al. Clinicopathological features and outcomes of gastric cancer patients with pulmonary lymphangitis carcinomatosa. Jpn J Clin Oncol 2014;44:792-8.

66. Yamauchi M, Yamada E, Miyaishi S, et al. Lung metastasis from gastric cancer. Gann no Rinsho (Jpn J Cancer Clin) 1982;28:1243-8.

67. Bleyer A, O'Leary M, Barr R, et al. Cancer Epidemiology in Older Adolescents and Young Adults 15 to 29 Years of Age, Including SEER Incidence and Survival: 1975-2000, NIH Pub. No. 06-5767. Bethesda, MD: National Cancer Institute, 2006.

68. Pfannschmidt J, Hoffmann H, Dienemann H. Thoracic metastasectomy for nonseminomatous germ cell tumors. J Thorac Oncol 2010;5:S182-6.

69. Johnston M, De Perrot M. Metastatic cancer to the lung. In: Devita V Jr, Hellman S, Rosenberg SA, editors. Cancer, Principles and Practice of Oncology, 7th edition. Philadelphia: Lippincott Williams \& Wilkins, 2005.

70. Yhim HY, Han SW, Oh DY, et al. Prognostic factors for recurrent breast cancer patients with an isolated, limited number of lung metastases and implications for pulmonary metastasectomy. Cancer 2010;116:2890-901.

71. Planchard D, Soria JC, Michiels S, et al. Uncertain benefit from surgery in patients with lung metastases from breast carcinoma. Cancer 2004;100:28-35.

72. Casiraghi M, De Pas T, Maisonneuve P, et al. A 10-year single-center experience on 708 lung metastasectomies: the evidence of the "international registry of lung metastases". J Thorac Oncol 2011;6:1373-8.

73. Marincola FM, Mark JB. Selection factors resulting in improved survival after surgical resection of tumors metastatic to the lungs. Arch Surg 1990;125:1387-92; discussion 1392-3.

74. Girard P, Baldeyrou P, Le Chevalier T, et al. Surgery for pulmonary metastases. Who are the 10 -year survivors? Cancer 1994;74:2791-7. 